Second, the postoperative course after standard aortic valve replacement was uneventful, despite the important comorbidities of the patient that suggested PAVI. Therefore an accurate preoperative evaluation is fundamental to identify those patients who are not suitable for the standard surgical procedure.

\title{
Totally percutaneous valve replacement for severe aortic regurgitation in a degenerating bioprosthesis
}

\author{
Massimo Napodano, MD, ${ }^{\mathrm{a}}$ Ada Cutolo, MD, ${ }^{\mathrm{a}}$ Chiara Fraccaro, MD,${ }^{\mathrm{a}}$ Giuseppe Tarantini, MD, PhD, ${ }^{\mathrm{a}}$ \\ Raffaele Bonato, MD, ${ }^{\mathrm{b}}$ Roberto Bianco, MD,${ }^{\mathrm{c}}$ Gino Gerosa, $\mathrm{MD},{ }^{\mathrm{c}}$ Sabino Iliceto, ${ }^{\mathrm{a}}$ and \\ Angelo Ramondo, MD, ${ }^{\text {a }}$ Padova, Italy
}

Recently, the feasibility and safety of percutaneous aortic valve replacement (PAVR) has been reported in the treatment of degenerative aortic valve stenosis in patients at high-risk for surgical aortic valve replacement (AVR). ${ }^{1}$ However, so far this therapy has been limited to patients with severe stenosis of the native valve. We report the case of a patient with severe aortic regurgitation owing to bioprosthesis dysfunction who was successfully treated by implantation of a CoreValve (CoreValve Inc, Irvine. Calif) prosthesis with a totally percutaneous approach.

\section{CLINICAL SUMMARY}

An 84-year-old woman, with previous surgical AVR with a bioprosthesis (Biocor $25 \mathrm{~mm}$ stentless; (Biocor Industria e Pesguisa Ltda, Belo Horizonte, Brazil) and cardiac pacemaker implantation for severe aortic stenosis in 1998, was admitted to a community hospital because of pulmonary edema. Comorbidity included hypertension, chronic renal failure, and previous left hemicolectomy for bowel malignancy. Transthoracic echocardiogram revealed a severe transprosthetic aortic regurgitation caused by leaflet degeneration and prolapse; the left ventricle was enlarged with moderate impairment of systolic function. Despite medical treatment, clinical status rapidly worsened. The case was discussed with two different surgical teams, who deemed the patient at high risk for redoing AVR because of advanced age, the risks of the redo procedure, and comorbidities: the logistic EuroScore was $31.8 \%$. Thus,

\footnotetext{
From the Interventional Cardiology, ${ }^{\mathrm{a}}$ Institute of Anaesthesiology, ${ }^{\mathrm{b}}$ and Institute of Cardiac Surgery, ${ }^{\mathrm{c}}$ Department of Cardiac Thoracic and Vascular Sciences, University of Padova, Italy.

Received for publication June 9, 2008; accepted for publication July 6, 2008; available ahead of print Dec 22, 2008.

Address for reprints: Massimo Napodano, MD, Interventional Cardiology, Department of Cardiac Thoracic and Vascular Sciences, University of Padova, 2 via Giustiniani.35100. Padova. Italy (E-mail: massimo.napodano@gmail.com).

J Thorac Cardiovasc Surg 2009;138:1027-8

$0022-5223 / \$ 36.00$

Copyright (c) 2009 by The American Association for Thoracic Surgery

doi:10.1016/j.jtcvs.2008.07.061
}

the patient was transferred to our department to evaluate the feasibility of PAVR. Cardiac catheterization and angiography confirmed the severity of aortic regurgitation with left ventricular dysfunction, increased ventricular filling pressure, pulmonary hypertension, and decreased cardiac index. The computed tomographic scan of the aorta and iliac and femoral arteries showed a moderate degree of wall calcification in the ascending aorta, with aortic root and annular dimensions amenable for PAVR; the femoral and iliac arteries showed a caliber suitable for large sheath insertion. The procedure was performed with the patient under mild sedation and local anesthesia by a percutaneous retrograde approach. Over an $18 \mathrm{~F}$ sheath percutaneously inserted in the right femoral artery, the valve (29 mm, third-generation CoreValve Revalving system) was introduced and retrogradely advanced under fluoroscopic guidance over a stiff wire in the ascending aorta across the pre-existing prosthesis plane. After careful evaluation of prosthesis position by angiography, the prosthesis was progressively deployed and the delivery system retrieved. Aortic angiogram after deployment showed the correct positioning of the prosthesis with a trivial paravalvular leak (Figure 1); no transvalvular gradient was detected. Finally, the $18 \mathrm{~F}$ sheath was removed and hemostasis of the right femoral artery was successfully obtained by knotting the sutures of a prepositioned suture-based closure device (Prostar XL 10F; Abbott Vascular, Alameda, Calif). The in-hospital course was uneventful and the patient was discharged at home on day 6 after the procedure. Dual antiplatelet treatment was prescribed for 6 months. At 6 months' follow-up, the patient remained free of adverse events, with persistent New York Heart Association functional class I; a transthoracic echocardiogram confirmed good performance of the implanted prosthesis with neither aortic regurgitation nor significant transprosthetic gradient.

\section{DISCUSSION}

Recently, Wenaweser and associates ${ }^{2}$ reported the first case of CoreValve implantation for the treatment of aortic regurgitation in a degenerating bioprosthesis. They used 

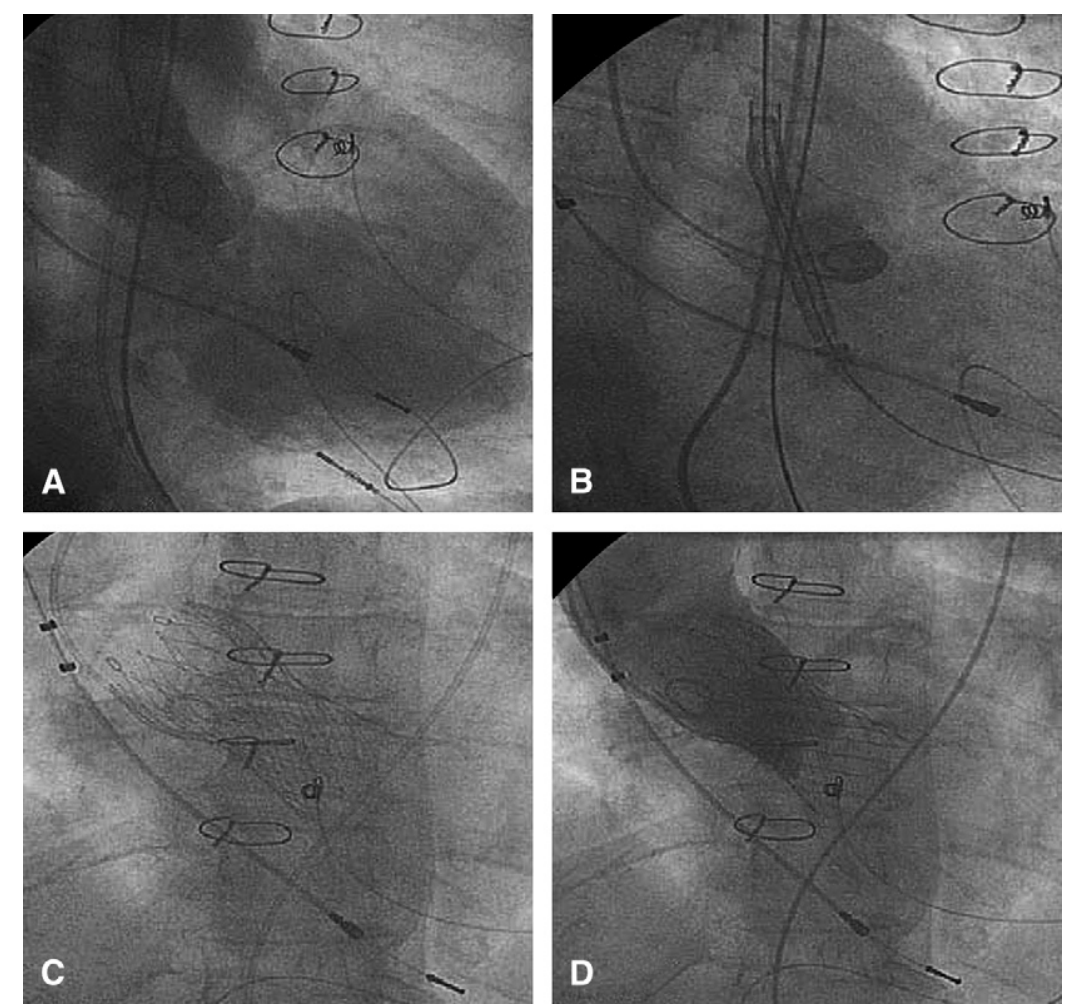

FIGURE 1. Aortic angiogram before (A) prosthesis implantation showing large aortic regurgitation; prosthesis positioning (B) and full deployment (C); aortic angiogram after prosthesis implantation showing no further aortic regurgitation (D).

general anesthesia with the hemodynamic support of a femoro-femoral bypass with surgical cutdown of arteries. We here reported, to the best of our knowledge, the first case of PAVR to treat a severe aortic regurgitation in bioprosthesis dysfunction. We used the third-generation CoreValve device, avoiding surgical cutdown of femoral arteries and the need for hemodynamic support. We thereby reduced the potential complications related to multiple large sheath placement and to hemodynamic pump use. In agreement with previous reports, our case confirms the feasibility of PAVR in aortic regurgitation caused by bioprosthesis dysfunction, with immediate hemodynamic improvement and persistent clinical benefit. In light of these evidences, it could be argued that stent-based valve implantation in degenerating prostheses may be more effective than in native valves; the latter usually present a higher amount of calcification, responsible for potential coronary ostial obstruction and inadequate stent sealing to the aortic root with subsequent residual paravalvular leak. ${ }^{3}$ We believe that PAVR with a self-expandable prosthesis may represent in the future an appropriate therapeutic alternative to surgical reintervention in elderly patients affected by bioprosthesis dysfunction. In fact, since the increase in life expectancy is leading to a huge number of patients undergoing AVR at advanced ages, with increasing use of bioprostheses, an expanding amount of bioprosthesis dysfunction in elderly patients with multiple comorbidities could be expected in the future. However, data regarding long-term follow-up in a large number of patients are needed to evaluate the real prognostic impact of this treatment.

\section{References}

1. Grube E, Schuler G, Buellesfeld L, Gerckens U, Linke A, Wenaweser P, et al. Percutaneous aortic valve replacement for severe aortic stenosis in high-risk patients using the second and current third generation self-expanding CoreValve prosthesis. J Am Coll Cardiol. 2007;50:69-76.

2. Wenaweser P, Buellesfeld L, Gerkens U, Grube E. Percutaneous aortic valve replacement for severe aortic regurgitation in degenerated bioprosthesis: the first valve in valve prosthesis using the CoreValve revalving system. Catheter Cardiovasc Interv. 2007;70:760-4.

3. Zedgy R, Ciobotaru V, Noghin M, Sleilaty G, Lafont A, Letremouille C, et al. Is it reasonable to treat all calcified stenotic aortic valves with a valved stent? Results from a human anatomic study in adults. J Am Coll Cardiol. 2008;51:579-84. 